\title{
Temporal and spatial variations of potential evaporation and the driving mechanism over Tibet during 1961-2001
}

\section{Haiyun SHI, Tiejian LI \& Guangqian WANG}

To cite this article: Haiyun SHI, Tiejian LI \& Guangqian WANG (2017): Temporal and spatial variations of potential evaporation and the driving mechanism over Tibet during 1961-2001, Hydrological Sciences Journal, DOI: 10.1080/02626667.2017.1332416

To link to this article: http://dx.doi.org/10.1080/02626667.2017.1332416

May 2017.

Submit your article to this journal $\pi$

Q View related articles $\asymp$

View Crossmark data $₫$ 
Publisher: Taylor \& Francis \& IAHS

Journal: Hydrological Sciences Journal

DOI: $10.1080 / 02626667.2017 .1332416$

Temporal and spatial variations of potential evaporation and the driving mechanism over Tibet during 1961-2001

\author{
Haiyun SHI $^{\mathrm{a}, \mathrm{b}, \mathrm{c}, *}$, Tiejian LI ${ }^{\mathrm{a}, \mathrm{c}}$, and Guangqian WANG ${ }^{\mathrm{a}, \mathrm{c}}$ \\ ${ }^{a}$ State Key Laboratory of Hydroscience and Engineering, Tsinghua University, Beijing, China \\ ${ }^{b}$ Department of Civil Engineering, The University of Hong Kong, Pokfulam, Hong Kong, China \\ 'State Key Laboratory of Plateau Ecology and Agriculture, Qinghai University, Xining, Qinghai,
}

\title{
China
}

Haiyun SHI: shihaiyun@tsinghua.edu.cn

Tiejian LI: litiejian@tsinghua.edu.cn

Guangqian WANG: dhhwgq@tsinghua.edu.cn

* Corresponding author (Dr. Haiyun SHI).

E-mail address: shihaiyun@tsinghua.edu.cn

Telephone: (00852)-2859-1970 
Revised manuscript for the Hydrological Sciences Journal

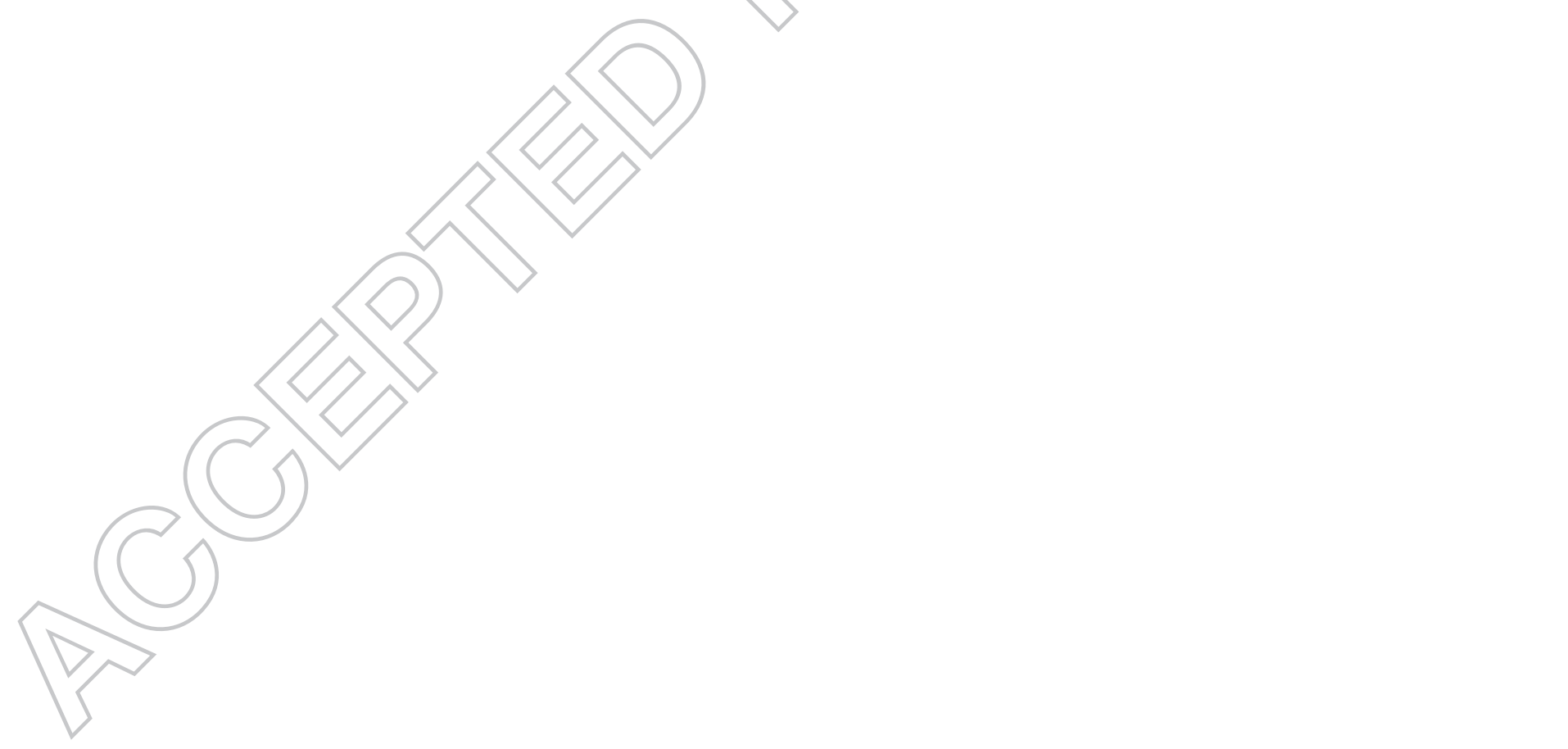




\section{Abstract}

Potential evaporation (PE), which is related to the water and energy exchange between the atmosphere and the Earth's surface, is the basic component of the global hydrological cycle and energy balance. This study detected the temporal and spatial variations of PE and related driving factors in Tibet, China, for the period 1961-2001, based on observed data recorded at 22 meteorological stations. The results showed that: (1) Tibet has experienced a statistically significant decrease of PE between 1961 and 2001, which mainly started from the 1980s along with accelerated warming; decreasing trends were detected in all seasons and all months except August and November; (2) the mean annual PE in Tibet showed an east-to-west increasing trend, and the annual PE recorded at most stations presented decreasing trends; (3) an inverse correlation of mean annual PE with elevation in this region was detected (low-to-high decreasing trend), and the statistical equations to estimate PE were established based on longitude, latitude and elevation; and (4) through analysing the relationships between $\mathrm{PE}$ and related meteorological variables, it is concluded that PE in Tibet can be well expressed by these variables, with vapour pressure deficit the dominant factor in determining PE. The results may help to understand the change features of PE and the driving mechanism for such regions; this would be valuable for hydrology and water resources research.

Key words potential evaporation; temporal trend; spatial distribution; driving mechanism; Tibet 


\section{INTRODUCTION}

As the basic component of hydrological cycle and energy balance, potential evaporation (PE hereafter) is closely related to the water and energy exchange between the atmosphere and the Earth's surface, and it is one of the basics of actual evapotranspiration (Xu and Singh 2005). In the past century, global climate change (e.g. the significant increase of air temperature) has exerted great impacts on the atmospheric water vapour content and circulation (IPCC 2007). As PE is regarded as a widely-used indicator in the fields of integrated water resources management, crop water requirements prediction, ecological environment assessment (Singh 1988, Jaramillo et al. 2013), it is necessary to investigate the temporal and spatial variations of PE for designated regions.

A number of studies have indicated that evaporation in the Northern Hemisphere was generally decreasing in the past several decades (Peterson et al. 1995, Brutsaert and Parlange 1998). The same phenomenon has been found in the studies on the trend analysis of PE in most regions of China (Liu et al. 2004, Cong et al. 2009), including the southwestern China (e.g. Tibet) (e.g. Chen et al. 2006, Zhang et al. 2007, Zhu et al. 2011, Li et al. 2014). Chen et al. (2006) reported that the annual PE decreased by 13.1 mm/decade since 1961 in the Tibetan Plateau and the surrounding areas, and wind velocity and relative humidity were found to be the most important factors affecting the PE trends. Zhang et al. (2007) showed that the decreased PE in the Tibetan Plateau was due to the decreases in wind velocity and net radiation, as well as the increase in air temperature. Zhu et al. (2011) pointed out that the annual PE in the Hengduan Mountains region had a 
statistically significant decreasing trend since the 1960 s, especially from the 1980 s to 1990s; air temperature, wind velocity and sunshine duration were the three dominant factors in determining PE. Li et al. (2014) indicated that southwestern China experienced a statistically significant decrease of PE in the period 1961-2009 and the decreased wind velocity was the main driving force.

Normally, PE can be influenced by related meteorological variables such as solar radiation, wind velocity, vapour pressure, air temperature and relative humidity (Valiantzas 2006, Singh 1988). In the past several decades, solar radiation and wind velocity have been decreasing in many regions worldwide (Stanhill and Cohen 2001, McVicar et al. 2008, Pryor et al. 2009). Similar results were also found in China, including the Tibetan Plateau (Zhang et al. 2007). Moreover, for regions with large elevation variations (e.g. mountainous regions), PE is characterized by significant spatial variation. Several studies indicated that PE generally decreases with elevation increase (Shevenell 1999, Houston 2006, Shi et al. 2014), and some other studies showed that PE can increase along with elevation increase (e.g. Nullet and Giambelluca 1990, Giambelluca and Nullet 1992).

The above-mentioned studies indicated that the temporal and spatial variations of PE are complicated and can be influenced by a variety of factors in different regions. For mountainous regions such as Tibet in China, it is valuable to explore the PE variability and to examine the driving mechanism behind it. Compared to previous studies (e.g. Chen et al. 2006, Zhang et al. 2007, Zhu et al. 2011, Li et al. 2014), the significance of this paper can be concluded as follows: first, this paper focuses on the region of Tibet rather than the Tibetan Plateau or southwestern China, and more meteorological stations over this study area are used in the hope of obtaining more reliable results of the PE temporal trends and 
spatial distributions. Second, this paper aims to investigate the relationship of PE with elevation, and statistical equations to estimate PE are established based on longitude, latitude and elevation. Third, this paper demonstrated that vapour pressure deficit was the most important factor in determining PE in Tibet through analysing the relationships between PE and related meteorological variables. Fourth, the modified Dalton model (Shi et al. 2014) and the Langbein model (Langbein 1949) were adopted to further strengthen the conclusions. This would be helpful to better understand the change features of PE and the driving mechanism in such regions.

\section{DATA AND METHODOLOGY}

\subsection{Study area and research data}

The study area, Tibet, is located in southwest China $\left(78^{\circ} 25^{\prime}-99^{\circ} 06^{\prime} \mathrm{E}, 26^{\circ} 50^{\prime}-36^{\circ} 53^{\prime} \mathrm{N}\right)$, with a total area of $1.2 \times 10^{6} \mathrm{~km}^{2}$ (Fig. 1). Tibet is the main body of the Qinghai-Tibet Plateau, and the mean elevation of this region is over $4000 \mathrm{~m}$ a.s.l. This region lies in the temperate zone, mainly dominated by a plateau monsoon climate. Normally, the maximum monthly PE occurs in May right before the rainy season, which is from June to September, and the minimum occurs in December.

There are 38 meteorological stations available in the study area (see Table 1 for details). Monthly meteorological data at these stations are available from the year of completion (the earliest is 1954) to 2001, and thus, the lengths of the datasets are different. As most of these stations were built in the 1950s, only the data from 1961 are used in this study to ensure that the lengths of the datasets from different stations are consistent. All the 
meteorological data were derived from the Hydrology and Water Resources Bureau of Tibet, China. For the designated station, the missing data are interpolated using the data from the neighbouring stations; however, stations with great discontinuity (i.e. five years) are excluded directly. After this elimination, 22 meteorological stations remain with complete monthly observations between 1961 and 2001. Nevertheless, the number of meteorological stations used is greater than that of the previous studies in the region of Tibet, i.e. nine in the study of Chen et al. (2006), 21 in the study of Zhang et al. (2007), and 16 in the study of Li et al. (2014).

Generally, PE cannot be directly measured; however, several studies have reported that it can be inferred from other measurements such as pan evaporation (Dibella et al. 2000, Ren et al. 2002, Liu et al. 2004, Fu et al. 2006). Therefore, the PE data used in this study are derived from pan evaporation measurements. And, for convenience, this paper refers to these derived PE data as the measured PE. The pan evaporation measurements are recorded by an $\mathrm{E}_{20}$ pan, which is an evaporimeter with a diameter of $20 \mathrm{~cm}$. Known from previous studies, the average conversion coefficient from $\mathrm{E}_{20}$ pan to E-601B pan (an evaporimeter with a diameter of $61.8 \mathrm{~cm}$ ) in Tibet is given as 0.65 (Ren et al. 2002) while the conversion coefficient from E-601B pan to $\mathrm{PE}$ is 0.9 (Dibella et al. 2000, Fu et al. 2006). As a result, the PE data used in this study are derived by using $E_{20}$ pan observations times a coefficient of $0.585(=0.9 \times 0.65)$. The annual and seasonal PE can be derived from the monthly values; moreover, in order to obtain the mean annual, seasonal and monthly PE values over Tibet, the measured PE data from different meteorological stations are interpolated to the centroid of Tibet, considering the different weights of all the stations. The yearly anomalies are achieved by removing the long-term means. In addition, it is worth noting that related 
meteorological data (i.e. vapour pressure, relative humidity, air temperature, surface temperature, sunshine duration, and wind velocity), which are used to analyse the impacts of these factors on PE, are all pretreated in the same way.

\subsection{Trend test and change point test methods}

The temporal variations of PE and related driving factors are analysed by using the trend test and change point test methods, as follows.

\subsubsection{Trend test method}

The Mann-Kendall trend test is a nonparametric rank-based statistical test method that was first proposed by Mann (1945) and further developed by Kendall (1975), and it is widely used in the fields of meteorology, hydrology and sedimentology (Changnon and Demissie 1996, Burn and Elnur 2002, Mu et al. 2007, Novotny and Stefan 2007, Shi and Wang 2015).

Based on the Mann-Kendall trend test method, the slope of the series can be computed by using the Thiel-Sen method (Thiel 1950, Sen 1968).

$$
\beta=\operatorname{median}\left(\frac{X_{j}-X_{i}}{j-i}\right) \text { for all } i<j
$$

where $X_{j}$ and $X_{i}$ are the observed values in the $j$ th and $i$ th year $(j>i)$, respectively.

Moreover, because the autocorrelation series is not applicable for the Mann-Kendall trend test method, prewhitening (von Storch and Navarra 1995) is required to eliminate the influence of the autocorrelation. 


$$
X p_{i}=X_{i+1}-r X_{i}
$$

where $X p_{i}$ is the observed value in the $i$ th year after prewhitening; and $r$ is the first-order autocorrelation coefficient of the series.

\subsubsection{Change point test method}

The Pettitt change point test (Pettitt 1979) is a nonparametric rank-based test used for the identification of a change point. The statistical parameter $U_{t, n}$ is given as follows:

$$
U_{t, n}=\sum_{i=1}^{t} \sum_{j=t+1}^{n} \operatorname{sgn}\left(X_{i}-X_{j}\right)=U_{t-1, n}+\sum_{j=1}^{n} \operatorname{sgn}\left(X_{t}-X_{j}\right)
$$

The probable change point $T$ should satisfy the condition of $K_{T, n}=\operatorname{Max}_{1 \leq k n}\left|U_{t, n}\right|$, and then, the relationship between $K_{T, n}$ and the $p$ value of Pettitt change point test which represents the significance level, can be expressed as.

$$
p=2 \exp \left[-\frac{6 K_{T, n}^{2}}{\left(n^{3}+n^{2}\right)}\right]
$$

For a designated $p$ value, the critical value of $K_{T, n}$ is computed first. Thereafter, each $U_{t, n}$ is compared with this critical value to find out the significant change point in the series. In this paper, the series is divided into two subsequences according to the first change point; and additional change points in these subsequences are determined if possible.

\subsection{Spatial interpolation method}

In order to compute the spatial distribution of PE over Tibet, a spatial interpolation method is necessary. There are several methods available, e.g. the Thiessen polygon method, inverse distance weighting (IDW) method, and the kriging method. Among these methods, 
the Thiessen polygon method, a purely geometric method, is the simplest one; however, its interpolation result is usually not satisfied. As a widely-used geometric method, the IDW method can present smoother and more accurate interpolation result than Thiessen polygon method (Goovaerts 2000, Shi et al. 2014, 2016a). The kriging method is a best-linearunbiased-estimation method, but it is difficult to determine its variogram; for accuracy, some studies (e.g. Tabios and Salas 1985) showed that this method can provide better results than the simpler methods (e.g. Thiessen polygon and IDW methods), while some others (e.g. Dirks et al. 1998) reached the opposite conclusion.

Considering the simplicity and the accuracy of interpolating meteorological variables, for this study we selected the IDW method. A general form of the method is given as follows:

$$
Z_{p}=\frac{\sum_{i=1}^{N} \frac{1}{D_{i}^{\beta}} Z_{i}}{\sum_{i=1}^{N} \frac{1}{D_{i}^{\beta}}}
$$

where $N$ is the number of used meteorological stations, $Z_{p}$ is the value at the point of interest, $Z_{i}$ is the value at the $i$ th given point, $D_{i}$ is the distance from the $i$ th given point to the point of interest, and $\beta$ is the power of $D_{i}$. Following common practice (Nalder and Wein 1998, Goovaerts 2000, Mito et al. 2011), this study adopted the value $\beta=2$, and the IDW method turns into the so-called inverse distance squared method. 


\subsection{Models for PE calculation}

In order to evaluate the relationships between PE and related meteorological variables, empirical models should be used to calculate PE with related meteorological variables for comparison. It is worth noting that only the sunshine duration data were measured at these stations. Although solar radiation can be calculated using the available data (e.g.) Allen 1998, Jaramillo et al. 2013, Jaramillo and Destouni 2014), a number of parameters need to be determined, which may introduce other errors to PE calculation. Therefore, a new modified Dalton model, which was proposed in our previous study (Shi et al. 2014), was adopted in this study. Besides vapour pressure deficit and wind velocity, this model includes the influences of both surface temperature and air temperature on PE. As it is established based on the measured meteorological data of the Lhasa River basin, Tibet, it has been proved to be useful to estimate PE over mountainous regions such as Tibet. Then, the monthly PE values can be calculated as follows (Shi et al. 2014):

$$
E=\left(0.2835+0.0082 u^{2}-0.0217 \Delta T\right)^{1 / 2} \exp \left(-0.0203 T_{a}\right)\left(e_{s}-e_{a}\right)
$$

where $E$ is the $\mathrm{PE}(\mathrm{mm}) ; e_{s}$ is the saturation vapour pressure corresponding to the surface temperature (hPa); $e_{a}$ is the air vapour pressure at the height of $1.5 \mathrm{~m}$ (for the meteorological stations used in this study) above the surface ( $\mathrm{hPa}) ; u$ is the wind velocity $(\mathrm{m} / \mathrm{s})$; and $\Delta T$ is equal to the surface temperature, $T_{s}$, minus the air temperature, $T_{a}\left({ }^{\circ} \mathrm{C}\right)$.

In addition, the other model used for PE calculation in this study is the Langbein model (Langbein 1949), which is only based on mean annual temperature. The simplicity of this model makes it useful for PE assessments in various simultaneous regions and global analysis (e.g. Shibuo et al. 2007, Asokan et al. 2010, Jaramillo et al. 2013, Jaramillo and 
Destouni 2014). The annual PE values can be estimated based on the following equation (Langbein 1949):

$$
E=325+21 T+0.9 T^{2}
$$

where $E$ is the PE (mm); $T$ is the mean annual air temperature $\left({ }^{\circ} \mathrm{C}\right)$.

\subsection{Assessment criteria}

To evaluate the relationships between PE and related meteorological variables, several objective functions, i.e. mean relative error (MRE), root mean square error (RMSE) and Nash-Sutcliffe coefficient of efficiency (NSCE; Nash and Sutcliffe 1970), are used as assessment criteria (see the Appendix for the respective equations).

\section{RESULTS}

\subsection{Temporal variation of PE}

\subsubsection{Inter-annual variation}

Based on the derived annual PE series (1961-2001), the trend test and change point test methods were used to investigate the change characteristics of the PE in Tibet. Further analyses were conducted to explain the cause.

The trend in the PE series was tested by using the Mann-Kendall method and linear regression method, respectively, and the conclusions derived from these two results were consistent (Fig. 2, Table 2). The mean annual PE was $1200 \mathrm{~mm}$ in Tibet in the period 1961-2001 and the annual PE series presented a decreasing trend $(p<0.1)$. However, the 
slope obtained from the Mann-Kendall method $(-9.1 \mathrm{~mm} /$ decade) was smaller than that obtained from the linear regression method $(-13.9 \mathrm{~mm} /$ decade $)$. This difference was likely due to the fact that the Mann-Kendall method can eliminate the abnormal vibration caused by external disturbance.

The change points in the PE series were tested by using the Pettitt method. The first change point for the annual PE series (1961-2001) was found in 1976, with a significance level of $p=0.1$ (Fig. 3(a)). The second change point in the sub-sequence of the annual PE series (1977-2001) was found in 1982, with a significance level of $p>0.1$ (Fig. 3(b)), which indicates that this change point was not a significant one; no additional change points could be found in other sub-sequences. As a result, the annual PE series was divided into three parts in this study: Period I (1961-1976), Period II (1977-1982) and Period III (1983-2001) (Fig. 2). In Period I, the mean annual PE was $1224 \mathrm{~mm}$, larger than the longterm mean value; and most of the anomalies were positive. Moreover, the annual PE decreased significantly at a rate of $-19.0 \mathrm{~mm} /$ decade in this period. However, a sudden drop in annual PE occurred in 1977, with a decrement of $92 \mathrm{~mm}$. Though the annual PE showed an increasing trend in Period II, the anomalies were all negative, which indicated that the annual PE stayed at a low level (i.e. the mean annual PE was $1151 \mathrm{~mm}$ ) in this period. Thereafter, in Period III, the annual PE decreased at a much larger rate of -30.5 $\mathrm{mm} /$ decade than that in the entire series (Fig. 2); the mean annual PE in this period was $1194 \mathrm{~mm}$. This decrease started in the 1980s and was mainly due to accelerated warming, which is consistent with the conclusions of some studies cited in the introduction section (e.g. Zhu et al. 2011, Li et al. 2014). 


\subsubsection{Seasonal and monthly variations}

To further investigate the change characteristics of PE in Tibet, the trends in the four seasons were also tested by using the Mann-Kendall method. In this study, spring is from February to April, summer is from May to July, autumn is from August to October, and winter is from November to January. The mean PE values of these four seasons were 270, 441, 323 and $166 \mathrm{~mm}$, respectively (Table 3). The mean PE in winter was the lowest, and this was less than $40 \%$ of that in summer. Figure 4 shows the temporal trends of the seasonal PE in Tibet in the period 1961-2001, and Table 3 lists the change rates and corresponding values of significance level. It is observed that PE presented the decreasing trends in all four seasons, with change rates of $-7.3 \mathrm{~mm} /$ decade in spring $(p<0.1),-3.8$ $\mathrm{mm} /$ decade in summer $(p>0.1),-2.1 \mathrm{~mm} /$ decade in autumn $(p>0.1)$ and $-1.9 \mathrm{~mm} /$ decade in winter $(p>0.1)$ (Table 3). Spring had the most pronounced decreasing trend, and the trends in other three seasons were not statistically significant. Moreover, Fig. 4 also demonstrates that the PE values stayed at a low level in Period II in all four seasons, consistent with the result of the mean annual PE.

With reference to monthly variation, the mean monthly PE showed decreasing trends in 10 months (all except August and November); and the highest change rate occurred in April (-3.8 mm/decade) with a significance level of $p<0.1$. However, only the trends in four months (February, April, June and September) were statistically significant $(p<0.1)$ (Table 4). On the one hand, this could largely explain the significant change rate of spring; on the other hand, the change rates of summer and autumn were expected to be dominated by those of June $(-2.5 \mathrm{~mm} /$ decade $)$ and September $(-1.6 \mathrm{~mm} /$ decade $)$. Moreover, the non- 
significant trends of November, December and January jointly determined the change rate of winter.

\subsection{Spatial variation of $P E$}

Using the IDW method and the observed data recorded at the 22 meteorological stations, the spatial distribution of the mean annual PE over Tibet in the period 1961-2001 was obtained (Fig. 5(a)). Tsetang station had the highest mean annual PE of $1567 \mathrm{~mm}$, while Lhari station had the lowest PE of $819 \mathrm{~mm}$. Generally, the mean annual PE in Tibet showed an east-to-west increasing trend.

The change rates of annual PE recorded at the 22 meteorological stations in the period 1961-2001 were calculated in this study, and then the relevant spatial distribution was obtained (Fig. 5(b)). It is observed that the annual PE recorded at 15 stations presented decreasing trends. Among them, Nyalam station had the highest change rate $(-78.8$ $\mathrm{mm} /$ decade, $p<0.1)$, followed by Shigatse station $(-54.3 \mathrm{~mm} /$ decade, $p<0.1)$ and Amdo station $(-48.1 \mathrm{~mm} /$ decade, $p<0.1)$. However, seven stations presented increasing trends, among which Shiquanhe station had the highest change rate $(49.0 \mathrm{~mm} / \mathrm{decade}, p<0.1)$, followed by Pagri station $(30.8 \mathrm{~mm} /$ decade, $p<0.1)$ and Lhasa station $(29.6 \mathrm{~mm} /$ decade, $p$ $<0.1$ ). In addition, the trends in most stations (i.e. 17 in 22) were statistically significant ( $p$ $<0.1)$.

\section{3,3 Relationship between PE and elevation}

As mentioned above, several studies (e.g. Shevenell 1999, Houston 2006, Shi et al. 2014) have shown the change feature of PE along with elevation change. Specifically, PE is 
inversely correlated with elevation in this region (Shi et al. 2014). Therefore, the relationship between PE (including the mean annual PE and the change rate of PE) and elevation in Tibet in the period 1961-2001 were analysed by using the observed data recorded at the 22 meteorological stations (Fig. 6). In this study, these 22 meteorological stations were divided into the following two groups: Group I included Lhari, Sog, Nyingchi, Dingqing, Bome, Qamdo and Zayu stations, which are located in eastern Tibet; while the other 15 stations were regarded as Group II. It is observed that the mean annual PE values of the stations in Group I were generally low, possibly due to the relatively humid climate affected by the South Asian monsoon; the decrease of PE with elevation was not remarkable (i.e. $-46 \mathrm{~mm} / \mathrm{km}$ ). In contrast, for Group II, a dramatic inverse correlation was found between the mean annual PE and elevation (i.e. $-267 \mathrm{~mm} / \mathrm{km}$, about six times as much as that of Group I). However, the $\mathrm{R}^{2}$ value $(0.19)$ was not high, which indicated that other factors should be considered. Figure 5(a) shows that the mean annual PE in Tibet presented east-to-west and south-to-north increasing trends. It is well known that geographical location (i.e. longitude and latitude) is an important factor in influencing $\mathrm{PE}$, as it can determine the distance between this location and oceans, which are the main sources of moisture. Thus, in order to establish the better relationship between PE and elevation, the geographical locations (i.e. longitude and latitude) of these meteorological stations were taken into account in this study, and the statistical equations to estimate PE for the two groups were obtained by using the multiple regression method:

$$
\begin{aligned}
& \mathrm{PE}_{\mathrm{I}}=-20.5 X+38.2 Y-0.12 Z+2128\left(R^{2}=0.32 ; p<0.1\right) \\
& \mathrm{PE}_{\mathrm{II}}=-15.9 X+70.9 Y-0.44 Z+2365\left(R^{2}=0.44 ; p<0.1\right)
\end{aligned}
$$


where $\mathrm{PE}_{\mathrm{I}}$ and $\mathrm{PE}_{\mathrm{II}}$ denote the mean annual $\mathrm{PE}(\mathrm{mm})$ of groups I and II, respectively; and $X, Y$ and $Z$ denote the longitude $\left(^{\circ}\right)$, latitude $\left(^{\circ}\right)$ and elevation $(\mathrm{m})$ of each meteorological station, respectively. Equations (8) and (9) indicated that the mean annual PE over Tibet had east-to-west, south-to-north, and high-to-low elevation increasing trends. However, with reference to the change rate of $\mathrm{PE}$, a dramatic inverse correlation was found for Group I (-8.6 mm/decade/km), while no significant trend was found for Group II(Fig. 6).

\subsection{Relationships between PE and related meteorological variables}

Potential evaporation can be affected by a variety of related meteorological variables, such as vapour pressure, wind velocity, solar radiation, relative humidity and temperature (Singh 1988). As a result, to investigate the dominant factor in determining PE in Tibet, the correlation features of PE with five related meteorological variables (i.e. vapour pressure deficit, air temperature, sunshine duration, wind velocity and relative humidity) were analysed based on the observed data recorded at the 22 meteorological stations in the period 1961-2001, and expressed by the Pearson correlation coefficient in this study (Table 5). It is observed that PE was closely correlated with all of these five meteorological variables. Among them, the correlations of PE with vapour pressure deficit, air temperature and sunshine duration were relatively obvious, while the correlations with wind velocity and relative humidity were relatively weak. The highest correlation coefficient between PE and vapour pressure deficit (0.844) demonstrated that vapour pressure was the most important factor in determining PE, while the significant influence of air temperature on

PE in this region has been proved in our previous study (Shi et al. 2014). Moreover, the correlations among these five meteorological variables were all statistically significant, 
indicating their interactions with each other. The lowest correlation coefficient between vapour pressure deficit and wind velocity $(-0.095)$ indicated that these two meteorological variables, which are regarded as the dominant variables of the Dalton model (Singh 1988), were relatively independent.

In this study, the temporal trends of these five related meteorological variables in Tibet in the period 1961-2001 were tested by using the Mann-Kendall method (Fig. 7). It is observed that vapour pressure deficit, sunshine duration and wind velocity presented decreasing trends, and only the trend of sunshine duration was statistically significant $(p<$ 0.1). In contrast, the other two variables (air temperature and relatiye humidity) presented increasing trends, both of them statistically significant $(p<0.1)$. The decrease of sunshine duration and the increase of relative humidity jointly restricted the transfer of water from the surface to the atmosphere, also leading to the decrease of PE. Moreover, as is well known, PE is proportional to vapour pressure deficit and wind velocity (Chow et al. 1988); and thus, the decreased vapour pressure deficit and wind velocity were the other two important driving factors, although their decreasing trends were not statistically significant. In addition, the temporal trends of related meteorological variables based on the three periods (periods I, II and III) were tested (see Fig. 7). It is observed that the increasing trend in annual PE in Period II was mainly caused by the increased vapour pressure deficit and sunshine duration.

In addition, Fig. 8 shows the scatter plots of the relationships between PE and the five related meteorological variables in Tibet in the period 1961-2001. It is observed that vapour pressure deficit had the strongest correlation with monthly PE, that is, higher vapour pressure deficit values corresponded to higher monthly PE values while lower 
vapour pressure deficit values corresponded to lower monthly PE values. This further proved the importance of vapour pressure in determining PE. Moreover, as the other dominant factor, wind velocity had a symmetrical distribution in its sub-plot, which was similar to that of vapour pressure deficit; however, the range of the points was much larger. In contrast, the distributions of the other three variables (i.e. air temperature, sunshine duration and relative humidity) were asymmetrical, and most of the points were located in the upper left parts of their sub-plots.

\section{DISCUSSION}

For Tibet or the surrounding areas, several studies have indicated that PE was generally decreasing in the past several decades, although dominated by different factors. Wind velocity was regarded as a dominant factor in determining PE by Chen et al. (2006), Zhang et al. (2007), Zhu et al. (2011), and Li et al. (2014); moreover, air temperature (Zhang et al. 2007, Zhu et al. 2011), relative humidity (Chen et al. 2006), and sunshine duration (Zhu et al. 2011) were considered to be the driving forces. However, based on the results of the present study, it is concluded that vapour pressure deficit was the most important factor in determining PE, followed by wind velocity. This is inconsistent with the conclusions of previous studies, and may be due to the differences in the study area, the number of meteorological stations, and the length and temporal resolution of the datasets used in different studies.

With reference to the relationship between PE and elevation, Chen et al. (2006) showed a significant negative correlation between annual trends of PE and elevation for 12 
stations above $4000 \mathrm{~m}$. Li et al. (2014) pointed out that only the trend magnitudes in summer and autumn displayed significant positive correlation with elevation. However, the conclusion of the present study was different. Both mean annual PE and change rate of PE derived from stations located in eastern Tibet (Group I) showed the significant negative correlation with elevation. In contrast, mean annual PE derived from stations in Group II showed the more significant negative correlation with elevation, but no significant trend was found in change rate of PE.

In addition, to further evaluate the relationships between PE and related meteorological variables, the modified Dalton model (Shi et al. 2014) and the Langbein model (Langbein 1949) were used to calculate the monthly and annual PE values, based on the measured meteorological data recorded at 22 meteorological/stations in the period 1961-2001. Figure 9 shows a comparison of the calculated PE values against the measured data. For the monthly PE values derived from the modified Dalton model, it is observed that the calculated values were generally close to the measured data, with a high NSCE of 0.85 . Moreover, the RMSE was only $15.5 \mathrm{~mm}$ and the MRE was only $2.9 \%$. Therefore, it is concluded that PE in Tibet can be well expressed by these related meteorological variables, including vapour pressure deficit, air temperature and wind velocity. For the annual PE derived from the Langbein model, it is observed that the calculated values were far from the measured data, and all the points were located in the lower right part of the sub-plot. The NSCE was -7.37 , and the RMSE $(740.6 \mathrm{~mm})$ and MRE $(-60.4 \%)$ were both quite large, indicating that this model was not credible for this region. Therefore, it is concluded that PE in Tibet cannot be expressed solely by air temperature. Ignoring the impacts of vapour pressure deficit and wind velocity can make the results unreasonable. Furthermore, 
it is worth noting that different results may be obtained by using other estimation methods, e.g. the Penman-Monteith equation. However, this method was not adopted in this study for the following reasons. First, as mentioned above, using the sunshine duration data measured at these stations to calculate solar radiation may introduce other errors to PE estimation. Second, similar to the Dalton model, vapour pressure deficit and wind velocity are also included in the Penman-Monteith equation, which may make it difficult to distinguish the importance of vapour pressure deficit and wind velocity through comparing the performances of these two methods.

Generally, sources of uncertainty can be data, model structure and parameters. It is worth noting that the spatial distribution of the meteorological stations in the study area is uneven. There is only one station (Shiquanhe) in the yast western part of the region, which may have had a negative effect on the PE spatial distribution (Fig. 5). Moreover, the PE estimation based on the locations of the stations (longitude, latitude and elevation) may be constrained by the limitation of data availability, and this can partly explain the reason why the $\mathrm{R}^{2}$ values of equations (8) and (9) were not high. Nevertheless, statistical equations to estimate the mean annual PE have been established in this study, which was not conducted in previous studies. The results would be more credible if better measured data can be obtained from a larger number of meteorological stations.

\section{CONCLUSIONS}

In this study, we detected the temporal trend and the spatial distribution of PE in Tibet in the period 1961-2001, and analysed the relationships of PE with elevation and related 
meteorological variables. The main conclusions of this study can be summarized as follows:

1. The annual PE presented a statistically significant decreasing trend in Tibet in the period 1961-2001, especially from the 1980s; moreover, decreasing trends were found in all the seasons and in 10 months (all except August and November).

2. The mean annual PE in Tibet showed an east-to-west increasing trend, and the annual PE recorded at 15 stations presented decreasing trends.

3. An inverse correlation of the mean annual PE and elevation in Tibet was detected, and the mean annual PE showed a low-to-high decreasing trend. Moreover, statistical equations to estimate PE were established based on longitude, latitude and elevation.

4 Through analysing the relationships between PE and related meteorological variables, it is concluded that PE can be well expressed by these related meteorological variables, with vapour pressure deficit the dominant factor in determining PE in Tibet.

This paper contributed to a better understanding of the changing features of $\mathrm{PE}$ and the driving mechanism for mountainous regions such as Tibet. This would be valuable for research in the fields of integrated water resources management, ecological environment assessment and climate change (e.g. Li et al. 2009, Shi et al. 2015, 2016b).

\section{Acknowledgements}


The authors are grateful to the Hydrology and Water Resources Bureau of Tibet for providing all the meteorological data. We are also grateful to the two anonymous reviewers who offered the insightful comments leading to improvement of this paper.

\section{Funding}

This study was supported by the Non-profit Fund Program of the Ministry of Water Resources of China (Grant no. 201501028), the National Natural Science Foundation of China funded project (Grant no. 51459003), the National Science \& Technology Pillar Program in the Twelfth Five-year Plan Period (Grant no. 2013BAB05B05), and the Hong Kong Scholars Program project (Grant no. XJ2014059).

\section{REFERENCES}

Allen, R.G., 1998. Crop evapotranspiration: guidelines for computing crop water requirements, FAO Irrigation and Drainage Paper no. 56. Rome: Food and Agricultural Organization.

Asokan, S.M., et al., 2010. Vapor flux by evapotranspiration: Effects of changes in climate, land use, and water use. Journal of Geophysical Research, 115, D24102.

Brutsaert, W. and Parlange, M.B., 1998. Hydrologic cycle explains the evaporation paradox. Nature, 396, 30.

Burn, D.H. and Elnur, M.A.H., 2002. Detection of hydrologic trends and variability. Journal of Hydrology, 255, 107-122. 
Changnon, S.A. and Demissie, M., 1996. Detection of changes in streamflow and floods resulting from climate fluctuations and land use-drainage changes. Climatic Change, 32, 411-421.

Chen, S.B., et al., 2006. Climatic change on the Tibetan Plateau: potential evapotranspiration trend from 1961-2006. Climate Change, 76, 291-319.

Chow, V.T., et al., 1988. Applied Hydrology. New York: McGraw-Hill Book Company.

Cong, Z.T., et al., 2009. Does evaporation paradox exist in China? Hydrology and Earth System Sciences, 13, 357-366.

Dibella, C.M., et al., 2000. Evapotranspiration estimates using NOAA AVHRR imagery in the Pampa region of Argentina. International Journal of Remote Sensing, 21(4), 791-797.

Dirks, K.N., et al., 1998. High-resolution studies of rainfall on Norfolk Island: Part II: Interpolation of rainfall data. Journal of Hydrology, 208(3-4), 187-193.

Fu, X.F., et al., 2006. Method for computation of potential evapotranspiration in Yarlung Tsangpo River Basin. Hydraulic and Hydropower Technology, 37(8), 5-8 (in Chinese).

Giambelluca, T.W. and Nullet, D., 1992. Evaporation at high elevations in Hawaii. Journal of Hydrology, 136(1-4), 219-235.

Goovaerts, P., 2000. Geostatistical approaches for incorporating elevation into the spatial interpolation of rainfall. Sournal of Hydrology, 228(1-2), 113-129.

Houston, J., 2006. Evaporation in the Atacama Desert: An empirical study of spatio-temporal variations and their causes. Journal of Hydrology, 330(3-4), 402-412.

IPCC (Intergovernmental Panel on Climate Change), 2007. Summary for policymakers. In: Climate change 2007: the physical science basis (S. Solomon et al. eds.). Contribution of Working Group I to the Fourth Assessment Report of the Intergovernmental Panel on Climate Change. Cambridge, UK: Cambridge University Press.

Jaramillo, F., et al., 2013. Multimethod assessment of evapotranspiration shifts due to non-irrigated agricultural development in Sweden. Journal of Hydrology, 484, 55-62. 
Jaramillo, F. and Destouni, G., 2014. Developing water change spectra and distinguishing change drivers worldwide. Geophysical Research Letters, 41, 8377-8386.

Kendall, M.G., 1975. Rank Correlation Measures. London: Charles Griffin.

Langbein, W.B., 1949. Annual runoff in the United States. US Geological Survey.

Li, T.J., et al., 2009. Modeling the Process of Hillslope Soil Erosion in the Loess Plateau. Journal of Environmental Informatics, 14(1),1-10.

Li, Z.X., et al., 2014. Spatial and temporal trend of potential evapotranspiration and related driving forces in Southwestern China, during 1961-2009. Quaternary International, 336, 127-144.

Liu, B.H., et al., 2004. A spatial analysis of pan evaporation trends in China, 1955-2000. Journal of Geophysical Research, 109, D15102.

Mann, H.B., 1945. Non-parametric tests against trend. Econometrica, 13, 245-259.

McVicar, T.R., et al., 2008. Wind speed climatology and trends for Australia, 1975-2006: capturing the stilling phenomenon and comparison with near-surface reanalysis output. Geophysical Research Letters, 35, L20403.

Mito, Y., et al., 2011. Multidimensional scaling and inverse distance weighting transform for image processing of hydrogeological structure in rock mass. Journal of Hydrology, 411(1-2), $25-36$

Mu, X.M., et al., 2007. Analysis of the impact of conservation measures on stream flow regime in catchments of the Loess Plateau, China. Hydrological Processes, 21, 2124-2134.

Nalder, I.A. and Wein, R.W., 1998. Spatial interpolation of climatic normals: test of a new method in the Canadian boreal forest. Agricultural and Forest Meteorology, 92, 211-225.

Nash, J.E. and Sutcliffe, J.V., 1970. River flow forecasting through conceptual models part 1 - A discussion of principles. Journal of Hydrology, 10(3), 282-290.

Novotny, E.V. and Stefan, H.G., 2007. Stream flow in Minnesota: Indicator of climate change. Journal of Hydrology, 334, 319-333. 
Nullet, D. and Giambelluca, T.W., 1990. Winter evaporation on a mountain slope, Hawaii. Journal of Hydrology, 112(3-4), 257-265.

Peterson, T.C., et al., 1995. Evaporation losing its strength. Nature, 377, 687.

Pettitt, A.N., 1979. A non-parametric approach to the change-point problem. Applied Statistics, 28(2), 126-135.

Pryor, S.C., et al., 2009. Wind speed trends over the contiguous United States. Journal of Geophysical Research, 114, D14105.

Ren, Z.H., et al., 2002. Conversion coefficient of small evaporation pan into E-601B Pan in China. Journal of Applied Meteorological Science, 13(04), 508-512 (in Chinese).

Sen, P.K., 1968. Estimates of the regression coefficient based on Kendall's tau. Journal of the American Statistical Association, 63, 1379-1389.

Shevenell, L., 1999. Regional potential evapotranspiration in arid climates based on temperature, topography and calculated solar radiation. Hydrological Processes, 13, 577-596.

Shi, H.Y., et al., 2014. Spatial distribution of monthly potential evaporation over mountainous regions: case of the Lhasa River basin, China. Hydrological Sciences Journal, 59(10), 18561871.

Shi, H.Y. and Wang, G.Q., 2015. Impacts of climate change and hydraulic structures on runoff and sediment discharge in the middle Yellow River. Hydrological Processes, 29(14), 3236-3246.

Shi, H.Y, et al., 2015. A service-oriented architecture for ensemble flood forecast from numerical weather prediction. Journal of Hydrology, 527, 933-942.

Shi H.Y., et al., 2016a. Spatial and temporal characteristics of precipitation over the Three-River Headwaters region during 1961-2014. Journal of Hydrology: Regional Studies, 6, 52-65.

Shi, H.Y., et al., 2016b. Physically-based simulation of the streamflow decrease caused by sediment-trapping dams in the middle Yellow River. Hydrological Processes, 30(5), 783-794. 
Shibuo, Y., et al., 2007. Hydrological responses to climate change and irrigation in the Aral Sea drainage basin. Geophysical Research Letters, 34, L21406.

Singh, V.P., 1988. Hydrologic Systems: Watershed Modeling. New Jersey: Prentice Hall.

Stanhill, G. and Cohen, S., 2001. Global dimming: a review of the evidence for a widespread and significant reduction in global radiation with discussion of its probable causes and possible agricultural consequences. Agricultural and Forest Meteorology, 107, 255-278.

Tabios, G.Q. and Salas, J.D., 1985. A comparative analysis of techniques for spatial interpolation of precipitation. Water Resources Bulletin, 21(3), 365-380.

Thiel, H., 1950. A rank-invariant method of linear and polynomial regression analysis, III. Proceedings of Koninalijke Nederlandse Akademie van Weinenschatpen, 53, 1397-1412.

Valiantzas, J.D., 2006. Simplified versions for the Penman evaporation equation using routine weather data. Journal of Hydrology, 331(3-4), 690-702.

von Storch, H. and Navarra, A., 1995. Analysis of Climate Variability: Applications of Statistical Techniques. Berlin: Springer-Verlag.

Xu, C.Y. and Singh, V.P., 2005. Evaluation of three complementary relationship evapotranspiration models by water balance approach to estimate actual regional evapotranspiration in different climatic regions. Journal of Hydrology, 308, 105-121.

Zhang, Y., et al., 2007. Trends in pan evaporation and reference and actual evapotranspiration across the Tibetan Plateau. Journal of Geophysical Research, 112, D12110.

Zhu, G.F., et al., 2011. Spatial distribution and temporal trends in potential evapotranspiration over Hengduan Mountains region from 1960 to 2009. Journal of Geographical Sciences, 22(1), 71 85 . 


\section{APPENDIX}

The equations used to compute mean relative error (MRE), root mean square error (RMSE) and the Nash-Sutcliffe coefficient of efficiency (NSCE) are given as follows:

$$
\begin{gathered}
\mathrm{MRE}=\frac{1}{N} \sum_{i=1}^{N}\left(\mathrm{PE}_{i, \text { cal }} / \mathrm{PE}_{i, \text { mea }}-1\right) \\
\mathrm{RMSE}=\sqrt{\frac{1}{N} \sum_{i=1}^{N}\left(\mathrm{PE}_{i, \mathrm{cal}}-\mathrm{PE}_{i, \text { mea }}\right)^{2}} \\
\mathrm{NSCE}=1-\frac{\sum_{i=1}^{N}\left(\mathrm{PE}_{i, \text { mea }}-\mathrm{PE}_{i, \text { cal }}\right)^{2}}{\sum_{i=1}^{N}\left(\mathrm{PE}_{i, \text { mea }}-\mathrm{PE}_{\text {mea }}\right)^{2}}
\end{gathered}
$$

where $\mathrm{PE}_{i, \text { mean }}$ and $\mathrm{PE}_{i, \text { cal }}$ are the $i$ th measured and calculated monthly $\mathrm{PE}$ values $(\mathrm{mm})$, respectively; $N$ is the sample size; and $\overline{\mathrm{PE}}_{\text {mea }}$ is the mean value of the measured data. 
Table 1 General information on the meteorological stations in Tibet. Stations in italic format are excluded from this study.

\begin{tabular}{|c|c|c|c|c|c|}
\hline $\begin{array}{c}\text { Station ID } \\
\text { number }\end{array}$ & Station name & $\begin{array}{c}\text { Longitude } \\
\left({ }^{\circ} \mathrm{E}\right)\end{array}$ & $\begin{array}{l}\text { Latitude } \\
\left({ }^{\circ} \mathrm{N}\right)\end{array}$ & $\begin{array}{c}\text { Elevation } \\
\text { (m a.s.l.) }\end{array}$ & $\begin{array}{l}\text { Year of } \\
\text { completion }\end{array}$ \\
\hline 55228 & Shiquanhe & 80.08 & 32.50 & 4278 & $(1961)$ \\
\hline 55248 & Gaize & 84.42 & 32.15 & 4415 & 1973 \\
\hline 55279 & Bangor & 90.02 & 31.38 & 4700 & 1957 \\
\hline 55294 & Amdo & 91.10 & 32.35 & 4800 & 1960 \\
\hline 55299 & Nagqu & 92.07 & 31.48 & 4507 & 1955 \\
\hline 55437 & Pulan & 81.25 & 30.28 & 3900 & 1973 \\
\hline 55472 & Xainza & 88.63 & 30.95 & 4672 & 1961 \\
\hline 55493 & Damxung & 91.10 & 30.48 & 4200 & 1963 \\
\hline 55569 & Lhatse & 87.60 & 29.08 & 4000 & 1978 \\
\hline 55572 & Namling & 89.10 & 29.68 & 4000 & 1998 \\
\hline 55578 & Shigatse & 88.88 & 29.25 & 3836 & 1956 \\
\hline 55585 & Nyemo & 90.17 & 29.43 & 3809 & 1974 \\
\hline 55589 & Gonggar & 90.98 & 29.3 & 3555 & 1998 \\
\hline 55591 & Lhasa & 91.03 & 29.72 & 3658 & 1955 \\
\hline 55593 & Maizhokung\& & 91.73 & 29.85 & 3804 & 1998 \\
\hline 55598 & Tsetang & 91.77 & 29.25 & 3552 & 1957 \\
\hline 55655 & Nyalam & 85.97 & 28.18 & 3810 & 1961 \\
\hline 55664 & & 87.08 & 28.63 & 4300 & 1959 \\
\hline 55680 & Gyangze & 89.60 & 28.92 & 4040 & 1957 \\
\hline 55681 & Nagarze & 90.40 & 28.97 & 4432 & 1998 \\
\hline 55690 & Tsonag & 91.95 & 27.98 & 4280 & 1961 \\
\hline 55696 & Lhunze & 92.47 & 28.42 & 3860 & 1960 \\
\hline 55773 & Pagri & 89.08 & 27.73 & 4300 & 1957 \\
\hline 56106 & Sog & 93.78 & 31.88 & 4023 & 1957 \\
\hline 56109 & Biru & 93.78 & 31.48 & 3940 & 1998 \\
\hline 56116 & Dingqing & 95.60 & 31.42 & 3873 & 1954 \\
\hline 56128 & Riwoqe & 96.60 & 31.22 & 3810 & 1998 \\
\hline 56137 & Qamdo & 97.17 & 31.15 & 3306 & 1954 \\
\hline 56202 & Lhari & 93.28 & 30.67 & 4489 & 1955 \\
\hline 56223 & Lhorong & 95.85 & 30.75 & 3640 & 1992 \\
\hline 56227 & Bome & 95.77 & 29.87 & 2736 & 1955 \\
\hline 56228 & Baxoi & 96.92 & 30.05 & 3260 & 1998 \\
\hline 56307 & Gyaca & 92.58 & 29.15 & 3260 & 1998 \\
\hline 56312 & Nyingchi & 94.47 & 29.57 & 3000 & 1954 \\
\hline
\end{tabular}




\begin{tabular}{lcllll}
56317 & Mainling & 94.22 & 29.22 & 2950 & 1998 \\
56331 & Zogang & 97.83 & 29.67 & 3780 & 1978 \\
56342 & Markam & 98.60 & 29.68 & 3870 & 1998 \\
56434 & Zayu & 97.47 & 28.65 & 2328 & 1960 \\
\hline
\end{tabular}


Table 2 Results of the trend test for the annual PE series using the Mann-Kendall method and the linear regression method, respectively.

\begin{tabular}{ccccc}
\hline Test method & $\begin{array}{c}\text { Mean } \\
(\mathrm{mm})\end{array}$ & $\begin{array}{c}\text { Slope } \\
(\mathrm{mm} / \text { decade })\end{array}$ & $\begin{array}{c}\text { Percentage } \\
(\% / \text { decade })\end{array}$ & Significance level \\
\hline Linear regression & & -13.9 & -1.1 & \\
Mann-Kendall & 1200 & -9.1 & -0.8
\end{tabular}


Table 3 Mean PE, change rates and the corresponding values of significance level, $p$, in different seasons in the period 1961-2001.

\begin{tabular}{ccccc}
\hline Season & Spring & Summer & Autumn & Winter \\
\hline Mean PE (mm) & 270 & 441 & 323 & 166
\end{tabular}

$\begin{array}{ccccc}\text { Change rate }(\mathrm{mm} / \text { decade }) & -7.3 & -3.8 & -2.1 \\ p & <0.1 & >0.1 & >0.1\end{array}$


Table 4 Mean PE, change rates and the corresponding values of significance level, $p$, in different months in the period 1961-2001.

\begin{tabular}{cccccccccccccc}
\hline Month & Jan. & Feb. & Mar. & Apr. & May & Jun. & Jul. & Aug. & Sep. & Oct. & Nov. Dec & \\
\hline Mean PE (mm) & 52 & 62 & 93 & 114 & 146 & 153 & 142 & 124 & 108 & 91 & \\
$\begin{array}{c}\text { Change rate } \\
(\mathrm{mm} / \text { decade })\end{array}$ & -0.8 & -1.8 & -1.5 & -3.8 & -1.3 & -2.5 & -0.3 & 0.5 & -1.6 & -0.4 & 0.1 & -0.6 \\
$p$ & $>0.1$ & $<0.1$ & $>0.1$ & $<0.1$ & $>0.1$ & $<0.1$ & $>0.1$ & $>0.1$ & $<0.1$ & $>0.1$ & $>0.1$ & $>0.1$ \\
\hline
\end{tabular}


Table 5 Correlations between PE and related meteorological variables according to correlation analysis with the monthly meteorological data recorded at 22 stations in the period 1961-2001.

\begin{tabular}{|c|c|c|c|c|c|c|}
\hline $\begin{array}{c}\text { Meteorological } \\
\text { variable }\end{array}$ & $\begin{array}{l}\mathrm{PE}, E \\
(\mathrm{~mm})\end{array}$ & $\begin{array}{c}\text { Vapour } \\
\text { pressure } \\
\text { deficit, } \Delta e\end{array}$ & $\begin{array}{c}\text { Air } \\
\text { temperature, } \\
T\end{array}$ & $\begin{array}{c}\text { Sunshine } \\
\text { duration, } \\
D\end{array}$ & Wind & $\begin{array}{l}\text { Relative } \\
\text { umidity, } \\
\text { RH }\end{array}$ \\
\hline & & $(\mathrm{hPa})$ & $\left({ }^{\circ} \mathrm{C}\right)$ & (h) & & $(\%)$ \\
\hline$E$ & 1 & / & / & & & / \\
\hline$\Delta e$ & $0.844^{*}$ & 1 & / & & / & / \\
\hline$T$ & $0.605^{*}$ & $0.796^{*}$ & & $y$ & / & / \\
\hline$D$ & $0.446^{*}$ & $0.191 *$ & & 1 & I & I \\
\hline$u$ & $0.208 *$ & $-0.095^{*}$ & $-0.249 *$ & $0.234 *$ & 1 & I \\
\hline RH & & & $0.509^{*}$ & $-0.560 *$ & $-0.224^{*}$ & 1 \\
\hline
\end{tabular}

* examination of significance level $p=0.01$ is satisfied. 


\section{FIGURE CAPTIONS}

Fig. 1 Locations of the meteorological stations in Tibet.

Fig. 2 Temporal trends of annual PE in Tibet in the period 1961-2001.

Fig. 3 Results of the change point test for annual PE series using the Pettitt method.

Fig. 4 Temporal trends of seasonal PE in Tibet in the period 1961-2001.

Fig. 5 Spatial distributions of (a) mean annual PE and (b) the change rate of annual PE in Tibet, 1961-2001.

Fig. 6 Relationship between PE and elevation of each meteorological station in Tibet, $1961-2001$

Fig. 7 Temporal trends of the five related meteorological variables in Tibet, 1961-2001.

Fig. 8 Scatterplots of the relationships between PE and the five related meteorological variables in Tibet, 1961-2001.

Fig. 9 Comparison of calculated values with measured data recorded at 22 stations in Tibet in the period $1961-2001$. 


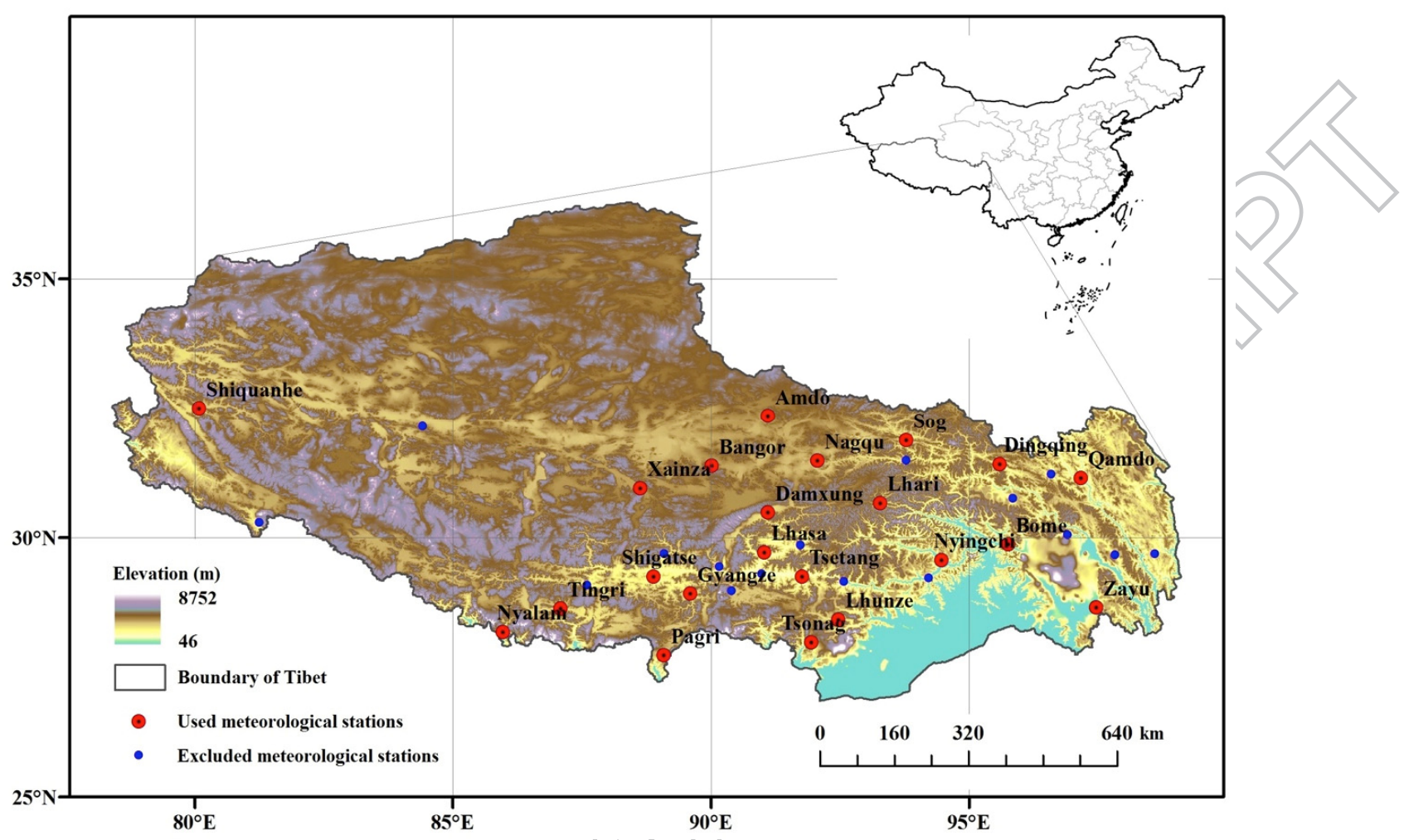

Fig. 1 


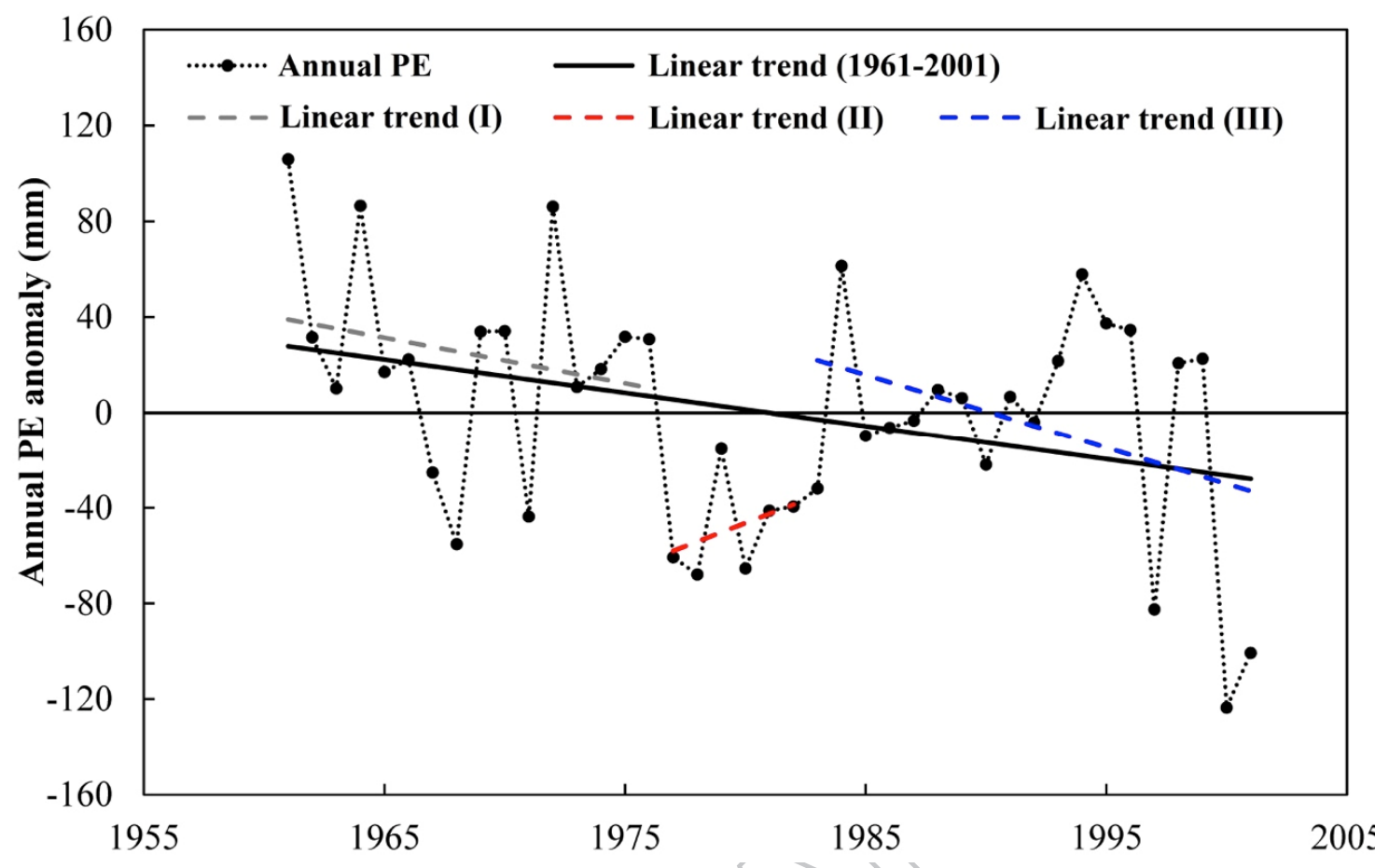

Fig. 2 

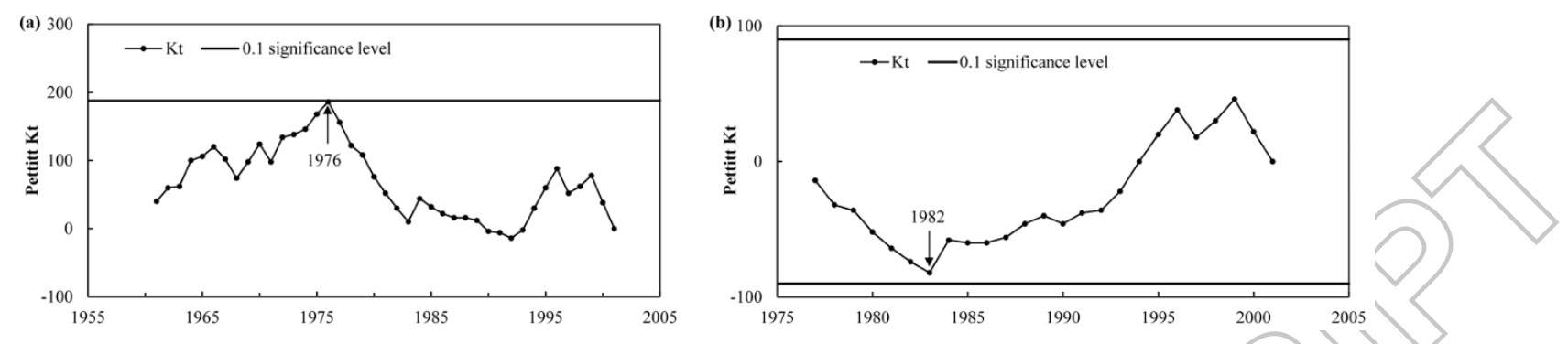

Fig. 3

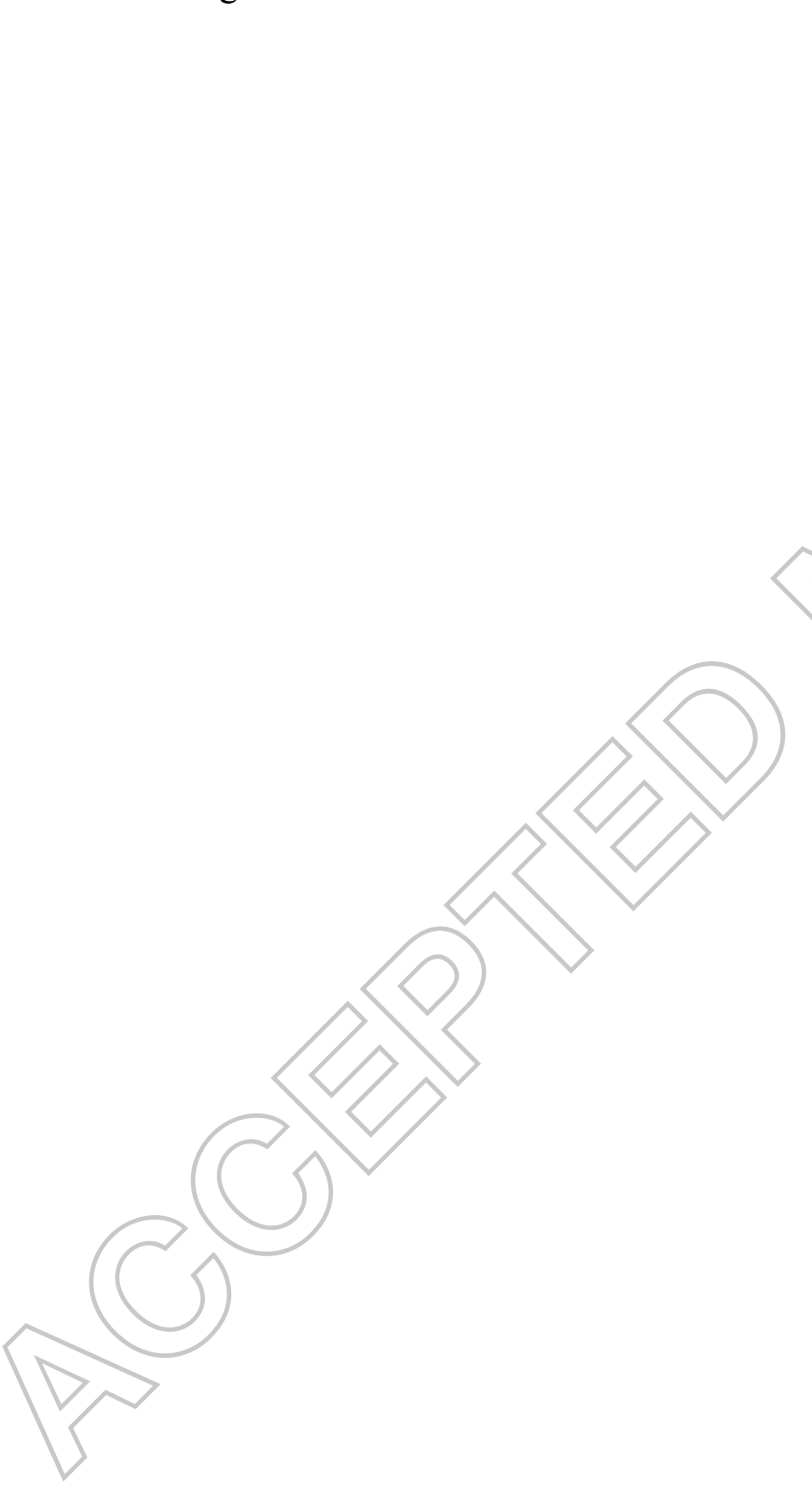



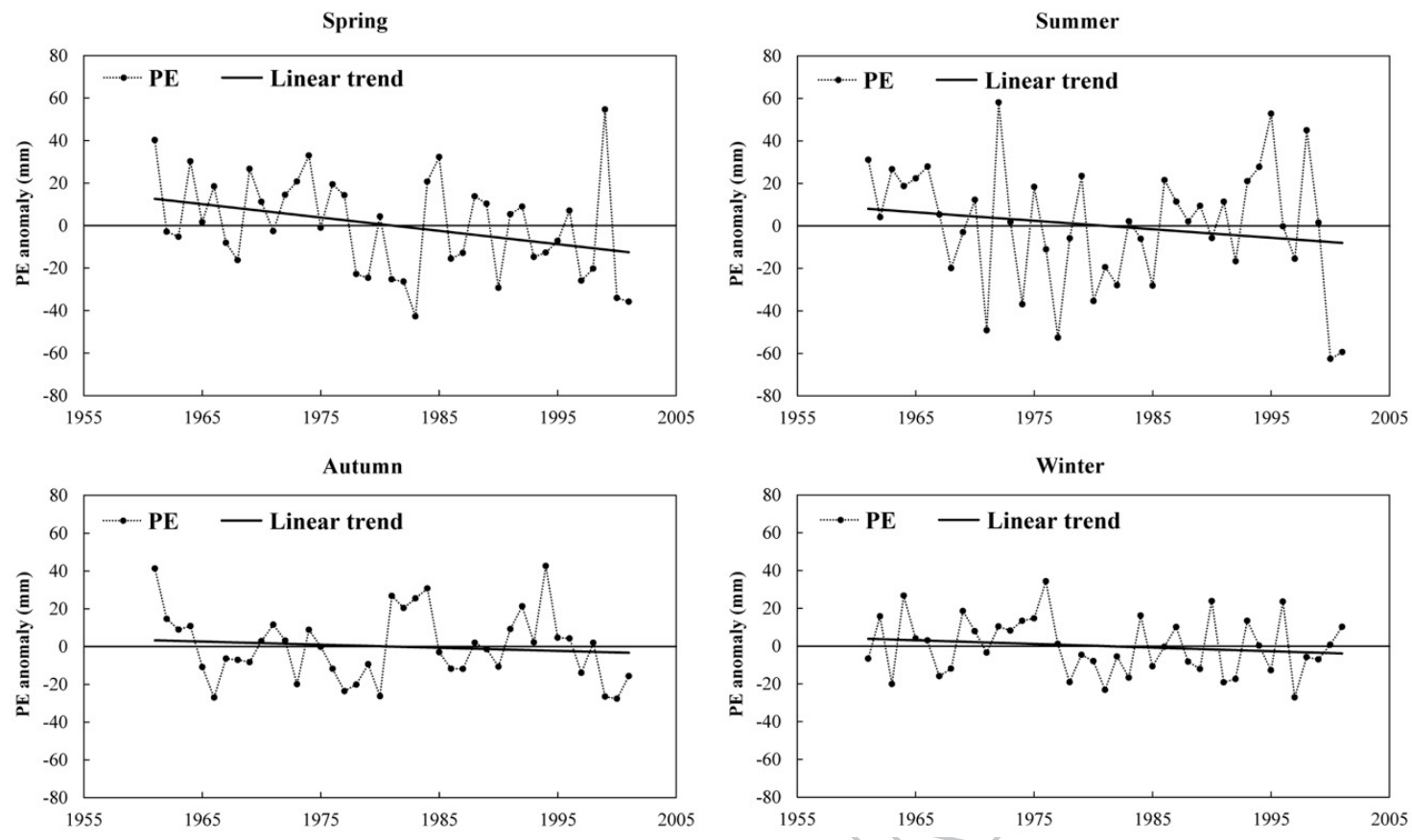

Fig. 4 

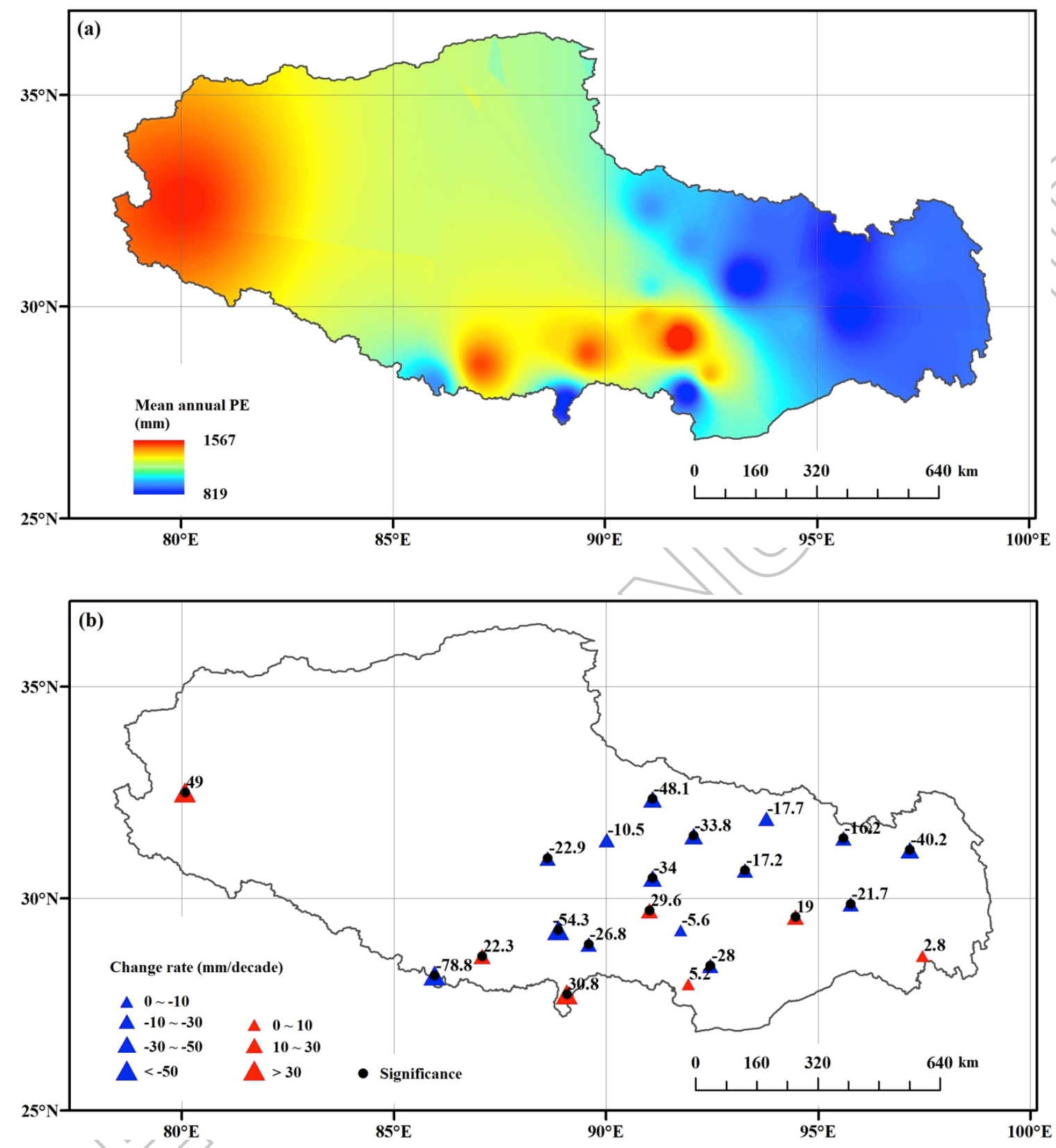

Fig. 5 

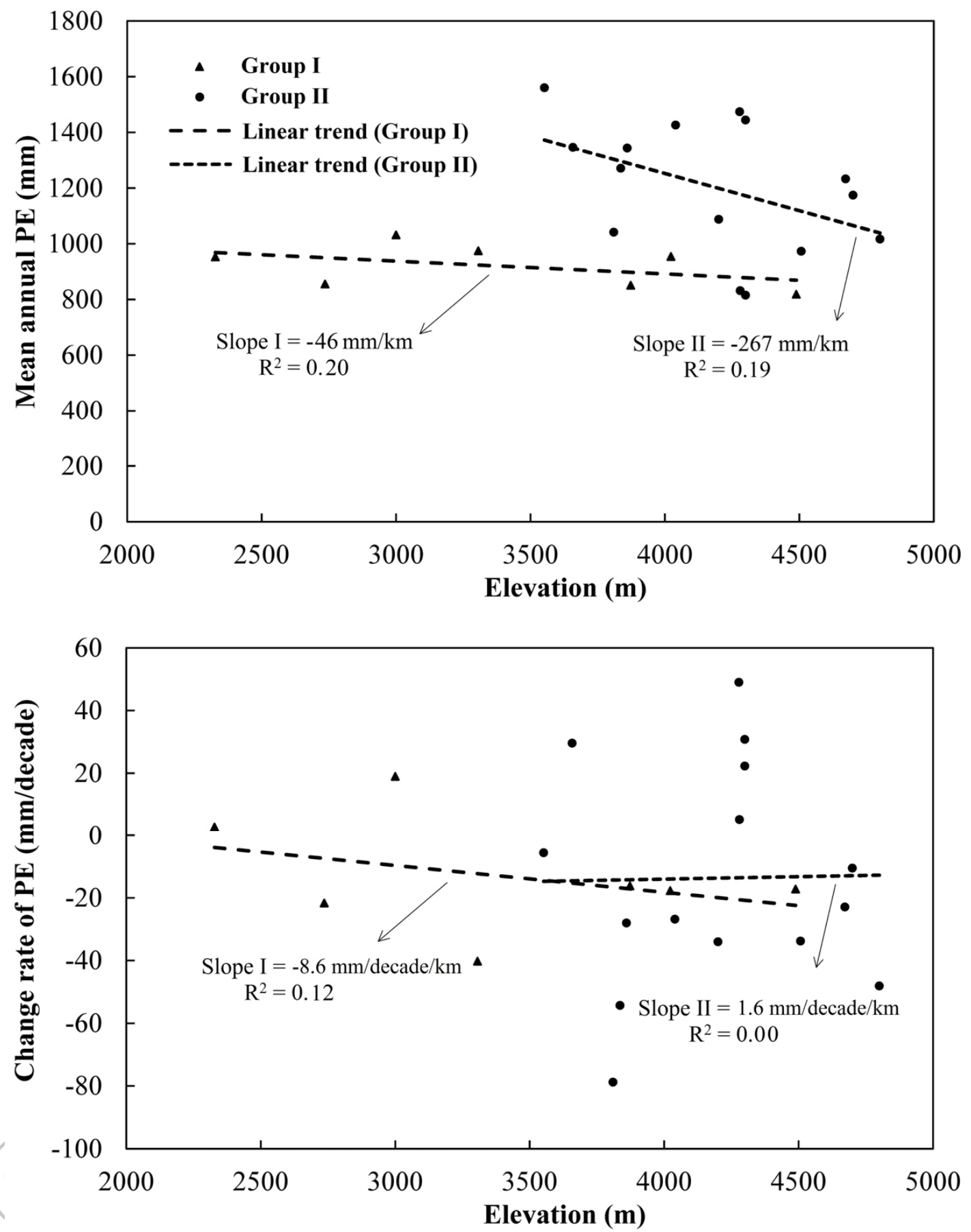

Fig. 6 

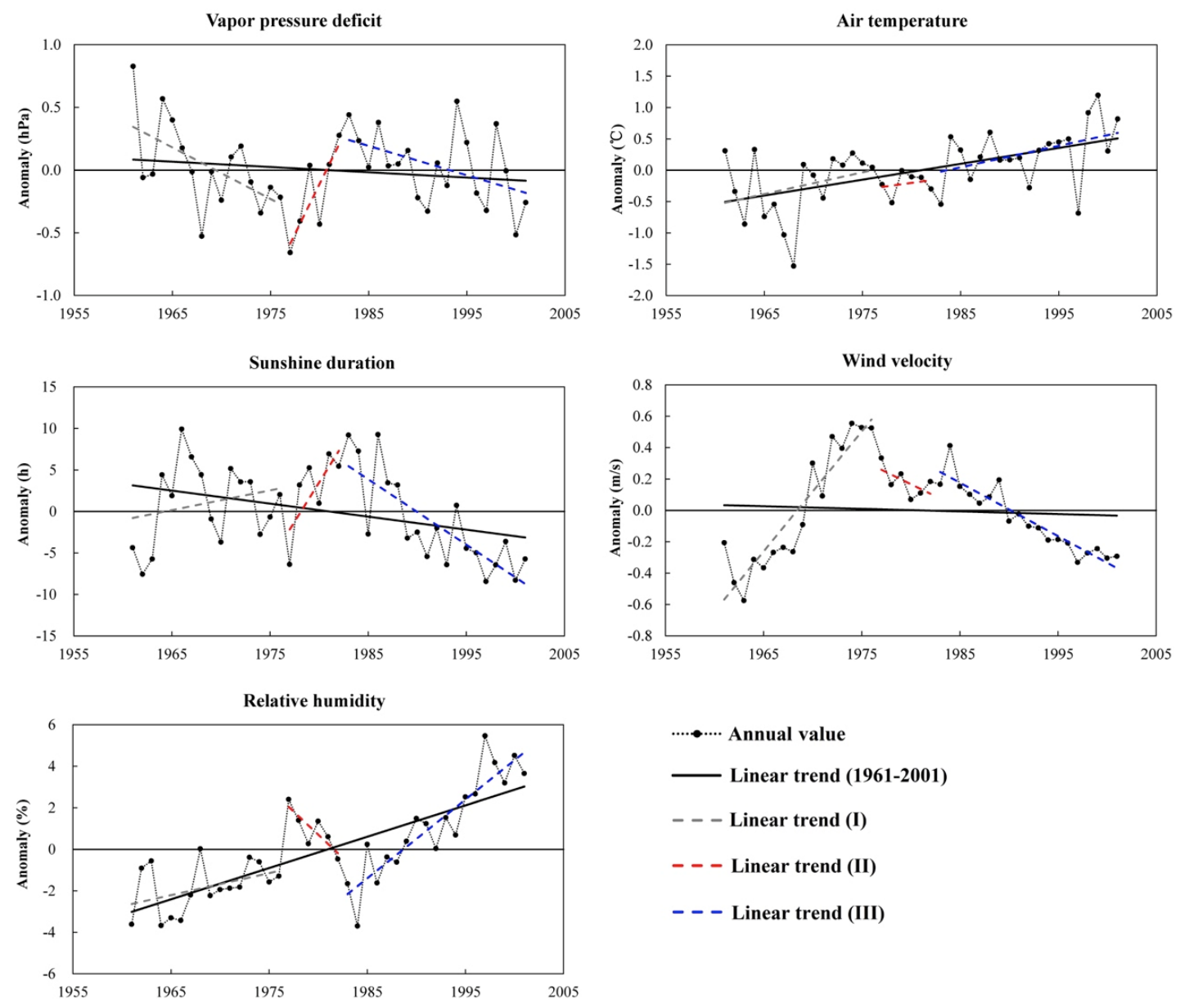

Fig. 7

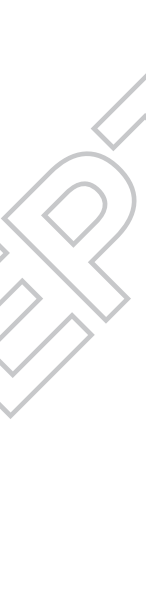



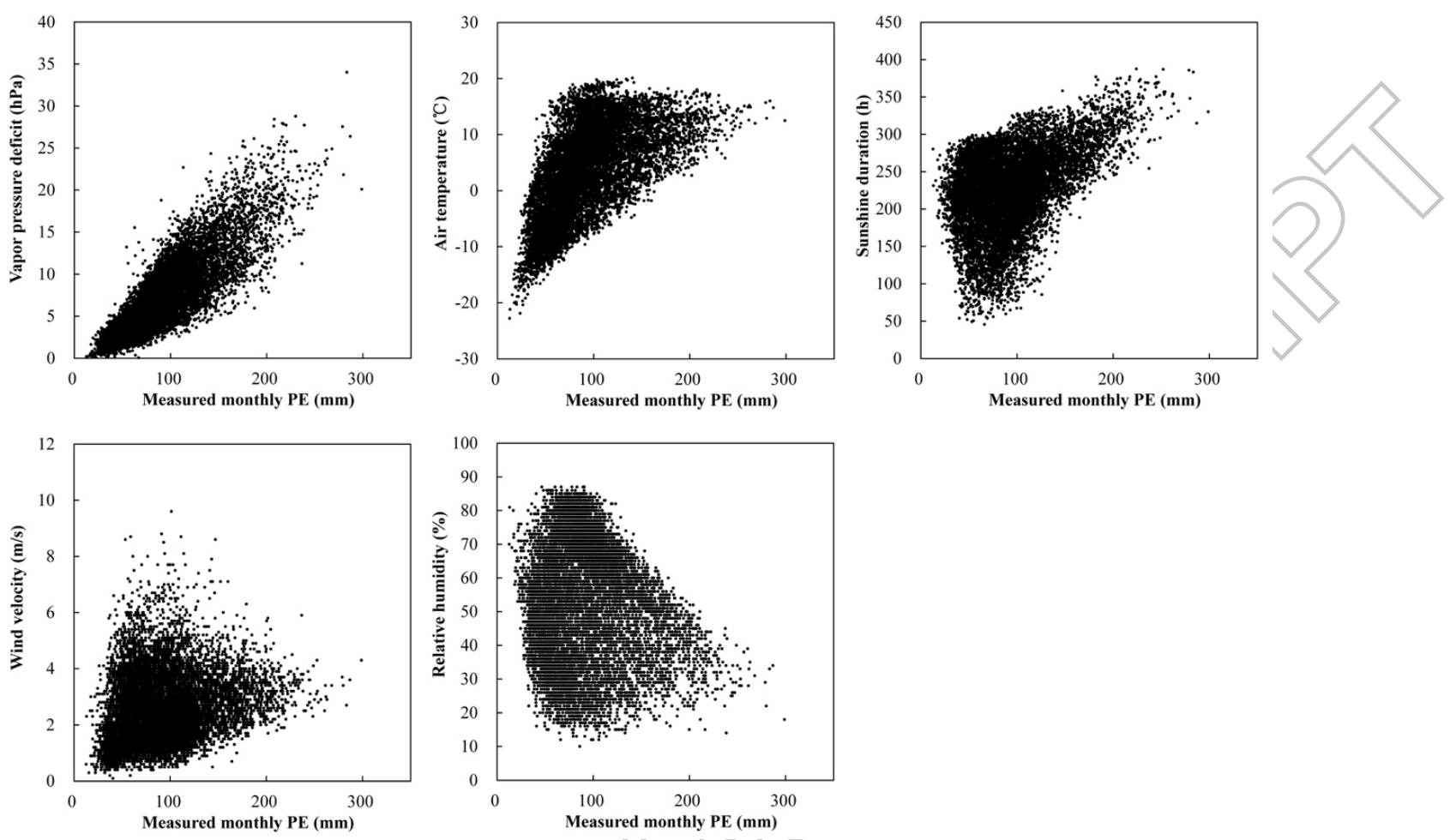

Fig. 8 

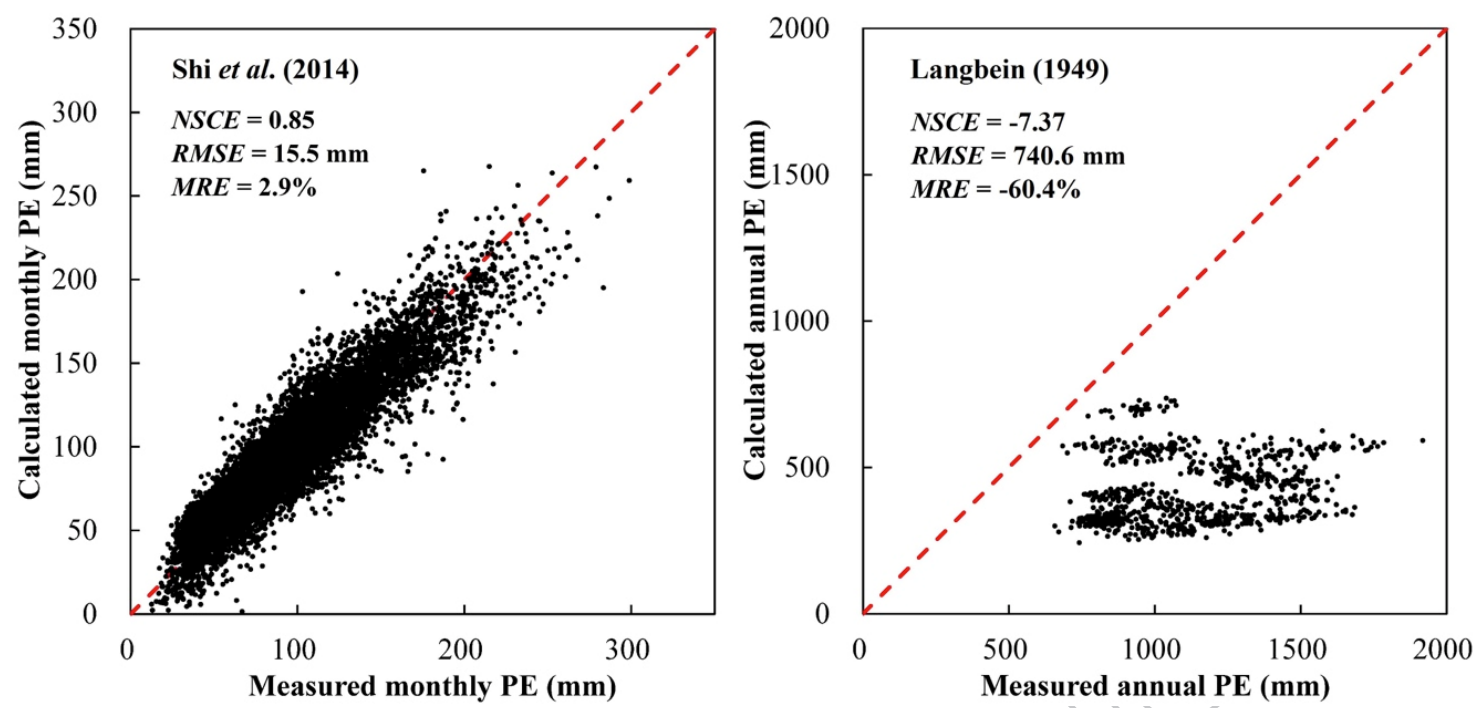

Fig. 9 